\title{
The Evolution of Approaches to Schizophrenia Diagnostics: from Kraepelin to ICD-11
}

\author{
Эволюция подходов к диагностике шизофрении: от Крепелина до МКБ-11 \\ doi:10.17816/CP62
}

\author{
(C) Alexander B. Shmukler \\ Moscow Research Institute of Psychiatry - a branch of the \\ V. Serbsky National Medical Research Centre of Psychiatry \\ and Narcology of the Ministry of Health of the Russian \\ Federation, Moscow, Russia
}

\author{
(C) Александр Б. Шмуклер \\ Московский научно-исследовательский институт \\ психиатрии - филиал Национального медицинского \\ исследовательского центра психиатрии и наркологии \\ им. В.П. Сербского Минздрава России, Москва, Роосия
}

\begin{abstract}
This article presents the evolution of views on schizophrenia diagnostics over the course of 150 years, beginning from the pre-Kraepelin period and ending with concepts developed in recent decades. Consideration is given to the merits and demerits of contemporary official classifications (DSM-5 and ICD-11) as well as to alternative approaches, particularly in relation to scientific research, and their prospects for development. Special attention is paid to the Research Domain Criteria Project (RDoC) of the National Institute of Mental Health (NIMH). Another promising area discussed in this paper relates to network analysis as a method for the investigation of psychotic disorders, particularly schizophrenia.
\end{abstract}

\section{АННОТАцИЯ}

В статье представлена эволюция взглядов на диагностику шизофрении на протяжении 150 лет, начиная с докрепелиновского периода и заканчивая концепциями, развиваемыми в последние десятилетия. Рассматриваются сильные и слабые стороны современных официальных классификаций (DSM-5 и ICD-11), а также альтернативные подходы, в том числе касающиеся научных исследований и перспективы их развития. Специальное внимание уделено the Research Domain Criteria Project (RDoC) of National Institute of Mental Health (NIMH). Другое перспективное направление, представленное в работе, касается сетевого анализа как метода изучения расстройств психотического спектра и, в частности, шизофрении.

\section{Keywords: schizophrenia; mental disorders; diagnostic criteria; classification of mental disorders Ключевые слова: шизофрения; психозы; диагностические критерии; классификация психических расстройств}

The history of describing schizophrenia as an independent clinical entity traces back to the dementia praecox concept of Emil Kraepelin., ${ }^{1,2}$ However, the term itself was not originated by Kraepelin but by Bénédict Morel who introduced it (démence précoce) to designate primary dementia. ${ }^{3}$ Prior to Morel, a point of view deriving from the theory of vesania developed by William Cullen, an English physician, dominated in psychiatry; in accordance with this theory dementia developed as a secondary phenomenon - a consequence of the destructive process, manifesting with different symptoms and signs, particularly affective disorders, followed by the addition 
of excitement ("intermittent insanity", in accordance with the terminology of French psychiatrists), with dementia developing only at the final stage. ${ }^{4}$ By contrast, Morel discussed primary dementia, moreover associating its early manifestation with degeneration and degradation. It was the latter idea, with its significant ideological overtones, that provoked antagonism in Morel's contemporaries and resulted in the neglect of the early dementia concept.

While Kraepelin borrowed the term from Morel, he virtually erased the author's intended content, as was noted by some psychiatrists at the time. Consolidating three types of mental condition: "chronic delusion with systematic evolution" (Magnan, 1893), ${ }^{5}$ catatonia (Kahlbaum, 1874) (6,7 $^{6}$ and hebephrenia (Hecker, 1871), ${ }^{8}$ with the subsequent addition of a fourth type - "dementia simplex" (Diem, 1903), ${ }^{9}$ Kraepelin identified a new clinical entity - early dementia. This identification was based on the following fundamental provisions: the endogenous nature of disorders, that is, the development of the disease in connection with the internal factors that aetiologically facilitate its occurrence (in contrast with exogenous factors related to external "hazards"); and the steady, progredient type of dementia development., ${ }^{1,2}$ Thus, the identification of this clinical entity was based on the combination of the disease aetiology, course and outcome.

Despite the fact that Kraepelin's scientific views underwent certain changes over time, deriving from the accumulation of new data, this did not alter the clinical approach, which implied the determination of patterns that would enable the interrelation of psychopathological symptoms, their dynamics, the overall course of the disease and its anticipated outcomes in the form of "extensive anomie with predominant emotion and will disorders, impotence of judgment and mental depletion".1 According to Kraepelin's concept, the basic symptoms of the disease included "disruption of interrelation between mental processes", disintegration of mentation, emotional depletion, passive dependence, negativism, stereotypies, mannerisms and impulsiveness. Thus, a dichotomy in mental pathology was substantiated through contra-distinction of dementia praecox and another endogenous disease: manic-depressive psychosis characterized by predominance of affective symptoms in clinical presentations, cyclical course and favourable prognosis. ${ }^{1,2}$
One of Kraepelin's key ideas was the necessity for dynamic consideration of the disease structure in contrast with the identification of permanent pathognomonic symptoms: "only the entire pattern in the aggregate within the whole period of development from the beginning to the end may give us the right to consolidate this observation with other homogeneous cases... the disease course and outcome correspond strictly to its biological essence".' In contrast to this approach, many well-known psychiatrists critical of Kraepelin's position persisted in attempts to identify "psychologically nonderivable" primary disorders that reflected the essence of this disease. These basic disorders were described as "intrapsychic ataxia" (Stransky), 10,11 "volitional weakness" (Mayer-Gross), ${ }^{12}$ and "hypoactivity of consciousness" (Berze). ${ }^{13,14}$ Bleuler's classification ${ }^{15}$ of the basic disorders included associative process splitting (association schism), affective apathy, autism and ambivalence ("the four As") as well as volition disorders (abulia) and disruption of cognitive processes (active attention, memory, unproductivity of intellectual activities). These symptoms and signs were considered in a static way, without any evaluation of the "primary disorder" and the disease outcome dynamics. Moreover, the nosological unity of the "schizophrenia group" was denied. But as in the case of dementia praecox, the diagnostic approach was based on negative symptoms.

The concept of positive and negative symptoms was introduced for the first time by John Russell Reynolds ${ }^{16}$, an English neurologist and psychiatrist, who considered these disorders as signs of the same abnormalities as occurred in case of epilepsy. He understood negative symptoms to mean those lacking functional manifestations, for example, in the form of sensory loss, paralysis or coma. From his point of view, positive symptoms were those that related to excessive functional manifestations: clonic convulsions, abnormal movements, hallucinations and delusion.

Further development of the concept of positive and negative symptoms was associated with the name of John Hughlings Jackson ${ }^{17}$ who not only considered positive and negative symptoms as different manifestations of the disease but also highlighted their interrelatedness. He considered negative symptoms as the core presentations of the disease - signs of degradation following from abnormalities in certain areas of the brain which are evolutionarily higher than other zones, responsible for 
the appearance of positive symptoms developing due to their excessive activity caused by lack of inhibitory influence from the affected areas. Thus, in accordance with the opinion of Hughlings Jackson, positive symptoms represent a secondary phenomenon, being the brain's reaction to the functional decline in the affected areas.

This point of view was dominant in diagnostics from the very beginning of schizophrenia's identification as an independent clinical entity, and persisted for many decades subsequently. Indeed, Kraepelin, Bleuler and other major psychiatrists of the 20th century particularly specified negative symptoms as the core presentations of schizophrenia. In this regard, the concept of schizophrenia developed by the Moscow scientific psychiatry school headed by Andrei Vladimirovich Snezhnevsky ${ }^{18,19}$ cannot be ignored. Within the framework of this concept, the idea of the "basic" mental disorder in the case of schizophrenia according to Bleuler was considered from the viewpoint of the dynamic approach proposed by Kraepelin and took into account interrelated patterns of the clinical signs and symptoms development, course and outcome of the disease. In this approach, positive and negative symptoms were described with reference both to each other and to the course of disease. The concept of the layer-by-layer structure of the brain (in its evolutionary aspect) developed by John Hughlings Jackson considered psychopathological symptoms (both negative and positive disorders) on a "layered" basis; in this case presentations at "higher" levels were thought to include underlying layers (for example, affective symptoms at a "lower" level could be included as an element of hallucinations and delusion).

Within the framework of this approach, diagnostics is performed not by the identification of individual disease signs that are connected together due to their specificity and high probability of co-occurrence, but rather with regard to the hierarchical relations of the clinical disease presentations, based on identification of a quite new formation - a complex set of symptoms reflecting the non-separable integrity of the disease components and assuredly representing more than just the sum of their constituents (symptoms and "simpler" syndromes). In this case the elements of a complex syndrome reflect the stage of its development, revealing the disease's anticipable dynamics and enabling predictions of its further development which are significant for diagnosing the state of the system and selection of treatment management.

However, this approach is becoming increasingly less common, even in the Russian Federation, and remains as an additional option only in a proportion of psychiatric facilities. The diagnostic concepts of the American Psychiatric Association (APA) ${ }^{20}$ and the corresponding diagnostic criteria for mental and behavioural disorders in the International Classification of Diseases (ICD) by the World Health Organization (WHO) ${ }^{21}$ have become dominant over recent decades.

\section{SCHIZOPHRENIA DIAGNOSTICS IN OFFICIAL CLASSIFICATIONS}

It should be noted that initially the APA diagnostic approaches to a great extent corresponded to the classic concepts of "old-school" psychiatry with regard to the "basic" disorder in the case of schizophrenia. Indeed, DSM-I (1952) and DSM-II (1968) paid significant attention to negative symptoms and the disruption of inter-personal relations. ${ }^{22}$ But DSM-III23,24 and DSM-III- $\mathrm{R}^{25}$ introduced operational criteria enabling the diagnostic requirements to be limited to the presence of chronicity and adverse outcomes of the disease through granting special status to the first-rank symptoms defined by Schneider ${ }^{26}$ that include thought echo, thought insertion or withdrawal, thought broadcasting, verbal pseudo-hallucinations in the form of commenting voices and/or their "dialogue", feelings of outside influence and delusional perceptions. In this regard it should be noted that initially these symptoms were proposed by the author to distinguish schizophrenia from manic-depressive psychosis and were not considered as specific to schizophrenia.

Nevertheless, the increase in the significance of first-rank symptoms for schizophrenia diagnostics along with exclusion of the signs of disease progression took place in DSM-IV and DSM-IV-TR. ${ }^{27,28}$ Further simplification of the diagnostic approach is noted in DSM-5: psychopathological nuances are ignored, and crucial significance is attached to the following three symptoms without their clinical differentiation: delusion, hallucinations and disorganized speech; while catatonia is referred to as a separate category (any catatonia symptoms are to be coded as co-morbid). ${ }^{20}$ Negative symptoms are included into the diagnostic criteria, but they are not mandatory for diagnosis, and their presence without any above-mentioned key symptoms precludes 
a diagnosis of schizophrenia. No distinct disease forms and disease course variants are specified.

The section on mental and behavioural disorders in ICD-11 is to a great extent harmonized with DSM-5, which is surely not incidental but rather reflects the deliberate intention of the team who drafted it. ${ }^{21}$ It should be noted that neuroscience data and genetic research have not brought about any considerable changes in the description of certain disorders and the general classification structure. The emphasis was placed on field research aimed at establishing a common understanding of disease presentations by clinicians and consistency of diagnostics. The significant efforts input by the drafting team enabled the desired result: the consistency of diagnostics was improved considerably in comparison with ICD-10. However, the atheoretical and consensual nature of this classification (that is, it results from specialist consensus) should not go unnoticed. Schizophrenia variants in ICD-11 are based only on the incidence of repeated attacks: a first episode, multiple episodes and a continuous course; and a distinction is made between cases with current symptoms, and those in partial or complete remission. In this presentation the possibility of recovery is not taken into account, although long-term studies demonstrate a sufficient probability of such an outcome - which happens in at least $16 \%$ of cases. ${ }^{29}$ In spite of the fact that the presence of affective (manic and depressive) symptoms, psychomotor and cognitive disorders remains possible apart from positive and negative symptoms, hallucination and delusional symptoms and/or disorganization of thinking are to be mandatory for a diagnosis of schizophrenia; negative symptoms are included in the diagnostic criteria but the presence of these symptoms alone does not permit a diagnosis of schizophrenia.

\section{ALTERNATIVE APPROACHES \\ TO SCHIZOPHRENIA DIAGNOSTICS}

In the last quarter of the 20th century, Tim Crow, an English psychiatrist, ${ }^{30,31}$ proposed distinguishing two sub-types of schizophrenia: variants with either predominantly positive or negative symptoms. The distinction was based not only on the difference in clinical aspects of the specified disease variants but also on pathogenetic differences: in the first case disturbances of dopaminergic system activity were observed, and in the second case inhibition mechanisms due to neuronal pruning played the key role in the disease pathogenesis.

Interest in negative symptoms has revived over recent years (although not affecting contemporary classifications) resulting in a distinction between deficit and non-deficit schizophrenia, considered to be different in the premorbid functioning of patients, clinical aspects of the disease (particularly the intensity of cognitive disorders), and functional outcomes. ${ }^{32}$ Additionally, mild neurological signs are more prominent in case of deficit schizophrenia as compared with the non-deficit variant, and deviations are detected more clearly in the course of neuro-imaging studies.

A two-factor model of negative symptoms in cases of schizophrenia has been developed..$^{33}$ Blunted affect and alogia are included into the first group, and anhedonia, asociality and avolition in the second. It is noted that decrease in the expression of emotion on the one hand, and avolition-apathy on the other, actually represent two different dimensions, which although highly correlated to each other have "differentiated predictivity" in relation to the clinical aspects of the disease, its functional outcomes, cognitive and emotional deficiencies as well as neurobiological disorders. Furthermore, it is postulated that primary and persistent negative symptoms include different psychopathological constructs, reflecting dysfunction arising from a different neurobiological formation. It is stated that further deconstruction of negative symptoms into more "elementary" components is necessary in order to understand the neurobiological mechanisms.

Ideas about the need for the "deconstruction" of schizophrenia are of increasingly frequent occurrence in scientific publications. ${ }^{34}$ Van $\mathrm{Os}^{35}$ proposed renaming this disease salience dysregulation syndrome, with the identification of three variants: with 1) affective expression, 2) developmental expression - negative symptoms and cognitive deficit, or 3 ) positive symptoms (hallucinations and delusion) and signs of disorganization. It is proposed that aberrant assignment of motivational salience of objects, people and actions should be considered as the core presentation of schizophrenia namely a disability in hierarchizing perceived stimuli with inversion of their salience (attribution of inappropriately high significance to any non-significant circumstances). Dopamine dysregulation is suspected to be the pathogenetic basis of such disorders. ${ }^{36}$ 
Another approach, the complete obverse of that applied in contemporary classifications, is proposed in the Research Domain Criteria Project (RDoC) from the US National Institute of Mental Health (NIMH). ${ }^{37}$ Five basic domains are identified within the framework of this project:

1) negative valence systems (the systems responsible for reactions to any negative situations - fear, anxiety, loss);

2) positive valence systems (the systems responsible for reactions to any positive situations - reward valuation, habits, reward leaning);

3) cognitive systems (attention, perception, memory, cognitive control);

4) systems for social processes (social cognitions: involvement; social communications, particularly perception of emotional face expressions, nonverbal communications; self-perception and selfconception; perception and understanding of other people);

5) activity / regulation systems (systems effecting the organism's sensitivity to any internal and external stimuli, maintenance of the relevant homeostatic regulation, circadian rhythms, sleep / awakening).

It is proposed to study these domains within the framework of seven basic areas: genes, molecules, cells, neural circuits, physiology, behaviours, self-reports. ${ }^{37}$

One more specific feature of this project is that while traditional research in psychiatry deals with the pathophysiology of mental diseases, and studies of their neurobiological markers, the RDoC attempts to understand how violations of the regulation of various systems leads to the clinical and psychopathological presentations of the diseases. The following questions are posed for the researcher: "what is the normal distribution of certain characteristics?", "which CNS system is responsible for these functions", and finally "is it possible to determine the 'quantity' of dysfunction and dysregulation which promotes shifting from the norm to disease at the level of mechanisms?". Within this project, there is an actual refusal to study schizophrenia as a separate nosological unit in favour of considering a group of psychoses as a whole and trying to highlight their diverse variants, based on the study of the pathophysiological mechanisms of the development of psychopathological symptoms.

\section{CONCLUSION}

At present it should be acknowledged that the psychopathological assessment of a patient's state remains the basis for diagnostics, in spite of abundant studies dealing with investigations of the neurobiological aspects of schizophrenia and schizophrenia-related disorders. In this case the applied criteria, although sufficiently valid and reliable $^{38}$ and useful for the purposes of statistical registration and analysis (and thus supported by health officials), turn out to have low acceptability for research and even for application in routine clinical practice. This is largely related to the refusal to differentiate and distinguish between the disease forms and course variants: when cases of various degrees of severity, process intensity and often with different clinical manifestations are analysed "in bulk", the average result produced prevents the identification of any patient sub-groups and more precise diagnostics of disorders detected within them.

It is obvious that further development of schizophrenia studies should be based on more differentiated approaches and the identification of patient groups with different variants of clinical aspects and their associated biological disease markers. It is supposed that the investigation of groups of neurobiological parameters rather than individual ones may turn out to be the most informative for the diagnostic aspect, offering the possibility for disease diagnostics with higher sensitivity and specificity. Network analysis that enables a comprehensive assessment of the existing disorders to be performed, with determination of interrelations between individual signs and their dynamic changes, is one such approach. The early results of these studies are promising, ${ }^{39}$ and further development of this area with analysis of extensive findings and an evaluation of a wide spread of parameters is required.

Conflict of interests: Author declare no conflict of interest. 
Funding: The article was prepared without external funding.

\section{Correspondence to:}

\section{Prof. Alexander B. Shmukler, MD}

shmukler.a@serbsky.ru

\section{For citation:}

\section{Shmukler AB. The evolution of approaches} to schizophrenia diagnostics: from Kraepelin to ICD-11. Consortium Psychiatricum. 2021;2(2):65-70.

\section{doi:10.17816/CP62}

\section{References}

1. Kraepelin E. Psychiatrie: ein Lehrbuch für Studierende und Aerzte. Verlag von Johann Ambrosius Barth; 1896.

2. Ebert A, Bar KJ. Emil Kraepelin: A pioneer of scientific understanding of psychiatry and psychopharmacology. Indian J Psychiatry. 2010;52(2):191-192. doi:10.4103/0019-5545.64591

3. Morel B. Traite des maladies mentales. Masson; 1860.

4. Doig A, Ferguson JPS, Milne IA, Passmore R, eds. William Cullen and the eighteenth century medical world. Edinburgh University Press; 1993.

5. Magnan V. Lecons cliniques sur les maladies mentalrs. Battaille; 1893.

6. Kahlbaum K. Die Katatonie oder das Spannungsirresein. Eine klinisch Form psychischer Krankheit. Hirschwald; 1874.

7. Kahlbaum KL. Catatonia or Tonic Insanity. In: Sass H. H, ed. Anthology of German Psychiatric Text. Blackwell Publishing Ltd;2007:106-124. doi:10.1002/9780470684351.ch9

8. Hecker E, Kraam A. 'Hebephrenia. A contribution to clinical psychiatry' by Dr. Ewald Hecker in Gorlitz. 1871. Hist Psychiatry. 2009;20(77 Pt 1):87-106. doi:10.1177/0957154X08099416

9. Diem O. Die einfach demente Form der Dementia praecox (Dementia simplex). Archive für Psychiatrie. 1903;37:111-187.

10. Kretzschmar C, Petit M. Erwin Stransky et l'ataxie intrapsychique. Encephale. 1994;20:377-383.

11. Triarhou LC. Erwin Stransky (1877-1962). J Neurol. 2012;259(9):20122013. doi:10.1007/s00415-012-6461-2

12. Mayer-Gross W. The Early Diagnosis of Schizophrenia. Br Med J. 1938;2(4061):936-939. doi:10.1136/bmj.2.4061.936

13. Berze J, Gruhle HW. Psychologie der Schizophrenie. J Springer; 1929.

14. Berze J. The Nature of psychic activity: an attempt at an energetic explanation. In: Sass H. H, ed. Anthology of German Psychiatric Text. Blackwell Publishing Ltd;2007:395-332. doi:10.1002/9780470684351.ch9

15. Bleuler E. Dementia Praecox order Grupper der Schizophrenien. Deuticke; 1911.

16. Buchwald J, Devinsky O. J. Russell Reynolds and the study of interictal symptoms in epilepsy. Arch Neurol. 1988;45(7):802-803. doi:10.1001/archneur.1988.00520310120028

17. Jackson JH. Selecting writings of John Hughlings Jackson. Hodder and Stoughton; 1931.

18. Snezhnevsky AV. The prognosis of schizophrenia. Int J Psychiatry. 1966;2(6):635-638.

19. Snezhnevsky AV. Evolution and nosological unity of schizophrenia. (Methods and results of investigation). Article in Russian. Vestn Akad Med Nauk SSSR. 1966;21(3):3-10.
20. American Psychiatric Association. Diagnostic and Statistical Manual of Mental Disorders, $5^{\text {th }}$ edition (DSM-5). American Psychiatric Association; 2013.

21. ICD-11 for Mortality and Morbidity Statistics. Mental, behavioural or neurodevelopmental disorders. Accessed April 5, 2021. https://icd. who.int/browse11/

22. Blashfield R. An evaluation of the DSM-II classification of schizophrenia as a nomenclature. J Abnorm Psychol. 1973;82(3):382389. doi:10.1037/h0035351

23. Spitzer RL, Andreasen NC, Endicott J. Schizophrenia and other psychotic disorders in DSM-III. Schizophr Bull. 1978;4(4):489-510. doi:10.1093/schbul/4.4.489

24. Fox HA. The DSM-III concept of schizophrenia. Br J Psychiatry. 1981;138:60-63. doi:10.1192/bjp.138.1.60

25. Kendler KS, Spitzer RL, Williams JB. Psychotic disorders in DSM-III-R. Am J Psychiatry. 1989;146(8):953-962. doi:10.1176/ajp.146.8.953

26. SchneiderK. Primary and secondary symptoms in schizophrenia. Fortschr Neurol Psychiatr Grenzgeb. 1957;25(9):487-490.

27. Flaum M, Andreasen NC. Diagnostic criteria for schizophrenia and related disorders: options for DSM-IV. Schizophr Bull. 1991;17(1):133-156. doi:10.1093/schbul/17.1.133

28. Tandon R, Bruijnzeel D, Rankupalli B. Does change in definition of psychotic symptoms in diagnosis of schizophrenia in DSM-5 affect caseness? Asian J Psychiatr. 2013;6(4):330-332. doi:10.1016/j. ajp.2013.05.011

29. Volavka J, Vevera J. Very long-term outcome of schizophrenia. Int J Clin Pract. 2018;72(7):e13094. doi:10.1111/ijcp.13094

30. Crow TJ. Positive and negative schizophrenic symptoms and the role of dopamine. Br J Psychiatry. 1980;137:383-386.

31. Crow TJ. The two-syndrome concept: origins and current status. Schizophr Bull. 1985;11(3):471-486. doi:10.1093/schbul/11.3.471

32. Kirkpatrick B, Mucci A, Galderisi S. Primary, Enduring Negative Symptoms: An Update on Research. Schizophr Bull. 2017;43(4):730736. doi:10.1093/schbul/sbx064

33. Strauss GP, Horan WP, Kirkpatrick B, et al. Deconstructing negative symptoms of schizophrenia: avolition-apathy and diminished expression clusters predict clinical presentation and functional outcome. J Psychiatr Res. 2013;47(6):783-790. doi:10.1016/j. jpsychires.2013.01.015

34. Jager M, Frasch K, Lang FU, Becker T. Deconstructing schizophrenia. Dimensional models or division into subtypes? Article in German. Nervenarzt. 2012;83(3):345-354. doi:10.1007/s00115-011-3255-1

35. van Os J. 'Salience syndrome' replaces 'schizophrenia' in DSM-V and ICD-11: psychiatry's evidence-based entry into the 21st century? Acta Psychiatr Scand. 2009;120(5):363-372. doi:10.1111/j.16000447.2009.01456.x

36. Kapur S. Psychosis as a state of aberrant salience: a framework linking biology, phenomenology, and pharmacology in schizophrenia. Am J Psychiatry. 2003;160(1):13-23. doi:10.1176/appi. ajp.160.1.13

37. Cuthbert BN. The RDoC framework: facilitating transition from ICD/DSM to dimensional approaches that integrate neuroscience and psychopathology. World Psychiatry. 2014;13(1):28-35. doi:10.1002/wps.20087

38. Bhati MT. Defining psychosis: the evolution of DSM-5 schizophrenia spectrum disorders. Curr Psychiatry Rep. 2013;15(11):409. doi:10.1007/s11920-013-0409-9

39. Shmukler AB, Kosytuk GP, Latanov AV, et al. Network analysis of cognitive, oculomotor and speech parameters in schizophrenia. Article in Russian. Zh Nevrol Psikhiatr Im S S Korsakova. 2020;120(62):54-60. doi:10.17116/jnevro202012006254 